\title{
A IMPORTÂNCIA DAS CIRURGIAS PARA CORREÇÃO DE FISSURA LABIOPALATINAS
}

\author{
Simone Ferreira Winter ${ }^{1}$ \\ Márcio Soldatelli Studzinski ${ }^{2}$
}

RESUMO: As fissuras labiopalatinas são malformações congênitas que atingem o lábio, o palato ou ambos. Apresenta uma etiologia variada, podendo envolver fatores genéticos e ambientais. Este estudo buscou, através de uma revisão bibliográfica, demonstrar para sociedade qual importância da cirurgia de correção de fissuras labiopalatinas para aumentar a qualidade de vida e bem estar do paciente, quebrando os preconceitos dos pais quanto a cirurgia. Foram consultados trabalhos encontrados nas bases de dados online Google Acadêmico, Biblioteca virtual de Saúde e catálogo de teses e dissertações. Para a busca foi utilizado os descritores em saúde "Fenda Labial", "Fissura Palatina", "Cirurgias corretivas", "Tratamento", foram utilizados na pesquisa têm data de publicação no período de 2015 a 2021, e engloba trabalhos na língua portuguesa. A classificação mais utilizada no Brasil é a de Spina, que divide as fissuras em 4 grupos, sendo eles fissura pré-forame incisivo, transforame incisivo, pós-forame incisivo e fissuras raras da face. $O$ tratamento cirúrgico das fissuras busca devolver anatomia, função e estética, devendo ser iniciado o quanto antes devido aos problemas que pode acarretar na fala, audição e cognição. $O$ Cirurgião-Dentista participa da reabilitação que acontece desde o nascimento até o final do crescimento do paciente com fissuras labiopalatinas. A primeira cirurgia realizada é a corretiva de lábio, também chamada de queiloplastia, é realizada até o $3^{\circ}$ mês de vida e a do palato, palatoplastia, entre os 9 a 12 meses, o que pode alterar de acordo com o centro especializado de reabilitação. Além das demais cirurgias para correção de outras alterações como as cirurgias nasais, funcionais ou estéticas que são realizadas na faixa etária que varia entre os 16 e 18 anos de idade. Conclui-se então que as cirurgias de correção das fissuras labiopalatinas são de extrema importância para melhora da qualidade de vida do paciente e de sua família de maneira geral.

Palavras chaves: Fissura Labial. Cirurgia Odontológica. Fissura Palatina.

ABSTRACT: The cleft lips were birth defect that reach lips, palate or both. Has a varied etiology, may involve genetics and environments factors. This paper search, thru a bibliographic review, prove for the society the important of the correction cleft lips surgery for increase the patients' quality of life and welfare, breaking the parents' bias about the surgery. Been consulted papers found in the online databases Scholar Google, Biblioteca Virtual de Saúde and Catálogo de teses e dissertações. For the search was "Cleft

\footnotetext{
I Graduação: Odontologia pela Faculdade: Unifasipe. E-mail:simonewinter2or7@outlook.com.

${ }^{2}$ Graduado em Odontologia - Univerdade de Passo Fundo. Especialista em Cirurgia e Traumatologia Bucomaxilofacial - Hospital São Vicente de Paula - Passo Fundo RS. Mestre em Promoção da Saúde UniCesumar - Maringá
} 
Lips”, "Cleft Palate”, “Correctives Surgery”, “Treatments”, were utilized for the research with date between 2015 to 2021, and encompass papers in Portuguese. The classification more utilized in the Brazil of the Spina, that divide the clefts in 4 groups, pursuant the region of the lesion. The cleft's surgery treatment quest brings back anatomy, function and esthetic, duty start as soon as possible due to problems that may occur in speech, hearing and cognition. The dentist take part in the rehab that happen since the patient's born until the final growth stage. The first surgery carry out is the lips corrective which is realized up to age of 3 months, and the palate surgery happen between the 9 to 12 months of life, what might change in agreement with the rehabilitation specialist center. Beyond the others surgeries for different changes, as nasal, functionals and aesthetic operations which are realized between 16 to 18 years old. In conclusion then that cleft lips surgery is the extreme important for improvement in the patient and family's life quality in the by and large.

Keys words: Cleft Lips. Surgery. Cleft Palate.

\section{INTRODUÇÃO}

As Fissuras Labiopalatinas (FLP) são malformações congênitas que atingem o lábio, o palato ou ambos. Ocorre em consequência do não fusionamento dos processos craniofaciais embrionários que originam palato primário e secundário, que deveria acontecer entre a quarta e a décima segunda semana de gestação. Está entre as malformações craniofaciais mais frequente na região cabeça e pescoço, com uma prevalência que varia entre r:500 e r:2500 nascidos vivos, sendo que no Brasil essa incidência varia entre 0,47 e 1,54 por Iooo nascidos e tem etiologia multifatorial, associada ou não aos fatores de hereditariedade e aos aspectos clínicos maternos como estresse, infecções, medicamentos e/ou irradiações (SCHÖNARDIE et al., 2021, MORAIS et al,.2020).

Por ter uma etiologia que envolve fatores genéticos e ambientais possui uma enorme complexidade, e sua base molecular continua em grande parte desconhecida, aliada a falta de informações e orientações para as famílias das crianças envolvidas, e ligada ao preconceito da sociedade, muitos pais não buscam apoio para o tratamento (MORAIS et al,.2020).

A classificação das FLP abrange as características anatômicas e a região acometida, sendo considerado o forame incisivo como ponto de referência morfológica e embrionária, organizadas em pré, pós ou transforme incisivo, também se dividem em unilaterais ou bilaterais e completas ou incompletas (SCHÖNARDIE et al., 2021). 
O tratamento cirúrgico das FLP tem o objetivo de devolver anatomia, função e estética para a área lesada pela deformidade, devendo iniciar o quanto antes devido aos problemas que podem acarretar na fala, audição, estética e cognição, além do impacto negativo que pode causar na integração social do paciente (SANTOS et al,2020).

Inicialmente $o$ tratamento busca melhorar a nutrição do lactente $e \quad o$ acompanhamento de seu ganho de peso, geralmente a cirurgia corretiva de lábio, também chamada de queiloplastia, é realizada até o $3^{\circ}$ mês de vida e a do palato, palatoplastia, entre os 9 a 12 meses, o que pode alterar de acordo com o centro especializado de reabilitação (MORAIS et al,.2020). Além das demais cirurgias para correção de outras alterações como as cirurgias nasais, funcionais ou estéticas que são realizadas na faixa etária que varia entre os I6 e i8 anos de idade (COSTAS; BORGES; ALMEIDA, 2020).

Uma das maiores barreiras que se pode ter sobre o tratamento das FLP se dá pelos resultados finais ocorrerem apenas ao fim do crescimento do paciente (COSTA et al., 202I). Independentemente de como ocorrer o tratamento clínico e cirúrgico, a importância do diagnóstico precoce e o acompanhamento por uma equipe multiprofissional composta por médicos, dentistas, fonoaudiólogos, geneticistas, nutricionistas e enfermeiros, é altamente recomendado (SANTOS; OLIVEIRA, 2021).

O Cirurgião-Dentista (CD) participa da reabilitação que acontece desde o nascimento até o final do crescimento do paciente com FLP, podendo estar incluída todas as especialidades da Odontologia para promover uma reabilitação adequada, devolvendo o sorriso e as funções ao paciente (COSTAS; BORGES; ALMEIDA, 2020).

Devendo o CD estar atento também à saúde geral do paciente, com a finalidade de orientar aos pais e responsáveis sobre promoção de saúde bucal, medidas preventivas, de reabilitação e auxílio na autoestima, não se limitando apenas ao tratamento odontológico (COSTA et al.,2021).

No ano de 1993 o Sistema Único de Saúde (SUS) começou a tratar pacientes com FLP com a introdução de procedimentos para correção e realização de implante dentário osseointegrado na tabela do Sistema de Informações Hospitalares do SUS, e em 1994, com a publicação da Portaria número 62, ficou estabelecido as normas para o cadastramento de serviços de reabilitação da FLP (ALMEIDA; CHAVES, 20ı9). 
Posteriormente conforme o PL 3.526 de 2019, foi determinado que o SUS através da sua rede de unidades públicas ou conveniadas deve fornecer serviços gratuitos de cirurgia plástica reconstrutiva e de tratamento pós-cirúrgico, abrangendo as especialidades de fonoaudiologia, psicologia e ortodontia, bem como de outras intervenções necessárias para a recuperação integral do paciente (COSTAS; BORGES; ALMEIDA, 2020).

Entre as vantagens do tratamento precoce dos defeitos provocados pela FLP estão a possibilidade de um melhor desenvolvimento para a musculatura da faringe e do palato, maior facilidade na alimentação, melhora no desenvolvimento da fonação, melhor funcionamento da tuba auditiva, maior facilidade para higienização, e melhora do estado psicológico dos pais e do bebê. Mas pode se colocar como desvantagens desse tratamento precoce a dificuldade da técnica em crianças de pouca idade e a formação de cicatriz resultante da cirurgia que pode levar a restrições no crescimento da maxila (COSTA et al.,2021).

Mas apesar dos benefícios do tratamento precoce o paciente adulto não é impedido de realizar o atendimento, especialmente quando este não pode ter acesso ao tratamento na infância. É importante o início precoce, mas nunca é tarde para buscar ajuda (COSTA et al.,2021). É possível ser realizado o diagnóstico no pré-natal pelo exame de Ultrassonografia (US), se haver um posicionamento da face, a fenda labial pode ser detectada no segundo trimestre de gestação, já a observação do palato é mais complexa e requer recursos tecnológicos mais sofisticados como US tridimensional (SANTOS; OLIVEIRA, 202I).

Com isso este trabalho busca responder à pergunta: Qual a importância das cirurgias de correção de FLP para melhor desenvolvimento do paciente?

Estudos demonstram a necessidade de cuidados referentes à alimentação, nas condições pré e pós correção cirúrgica, no preparo da equipe, para a higiene oral, qualidade da assistência e problemas comportamentais (MORAIS et al,.2020, SILVEIRA et al.,2020). E também há estudos que sugerem que em crianças pequenas com FLP o processo de desenvolvimento de fala e linguagem sofre um atraso, quando comparado com o de crianças na mesma faixa etária, porém sem a malformação, e notou-se também que esse atraso geralmente diminui com o aumento da idade (SCHÖNARDIE et al., 202I). 
Os pais de pacientes com FLP logo que recebem a notícia entram em um grande choque emocional, sendo que os padrões mais comuns de reação são negação, rejeição, sentimento de culpa, depressão e tristeza, mas aos poucos são substituídos pela aceitação, que aumenta a cooperação destes em relação ao tratamento (SANTOS; OLIVEIRA, 202I).

O portador de FLP pode enfrentar problemas sociais por ser visto como diferente, sofrendo discriminação, em alguns casos tem que lutar contra os preconceitos da comunidade e da família sobre sua capacidade e inteligência, e também para o desenvolvimento de sua problemática e dos procedimentos necessários para sua reabilitação, da parte dos educadores ou empregadores (SANTOS et al,2020).

O primeiro contato social da pessoa com FLP é com a família, que deve estar preparada para enfrentar situações de preconceito, uma vez que a sociedade valoriza a estética e a comunicação. Com isso esses indivíduos tem a necessidade de serem incluídos no ambiente social, econômico e cultural, garantindo a eles os seus direitos de cidadão (MORAIS et al,.2020). Assim entende-se que o tratamento de pessoas com FLP acrescenta aspectos funcionais, estéticos, psicossociais, e emocionais para sua vida (COSTAS; BORGES; ALMEIDA, 2020).

Este estudo busca demonstrar a sociedade qual importância da cirurgia de correção de FLP para aumentar a qualidade de vida e bem estar do paciente, quebrando os preconceitos dos pais quanto a cirurgia. Como objetivo geral busca explicar a importância da cirurgia de correção de FLP para o desenvolvimento do paciente, sendo os objetivos específicos explicar sobre as causas da fissura FLP e quais os tipos, explicar sobre os tipos de cirurgia e mostrar quais são os benefícios para a vida do paciente depois da cirurgia.

O presente trabalho trata de uma revisão de literatura, realizada com base em trabalhos encontrados nas bases de dados online: Google Acadêmico, Biblioteca virtual de Saúde e catálogo de teses e dissertações. Para a busca foi utilizado os descritores em saúde "Fenda Labial", "Fissura Palatina", "Fissura Labiopalatal”, "Cirurgias corretivas", “Tratamento". Os trabalhos utilizados na pesquisa têm data de publicação no período de 2015 a 2021, e engloba trabalhos na língua portuguesa. 


\section{Revisão de literatura}

\section{I Etiologia das Fissuras Labiopalatinas}

As FLP são uma das malformações craniofaciais que mais ocorrem atualmente, com uma prevalência geral que varia entre i:50o e i:2500 nascidos vivos e no Brasil essa prevalência é de I a cada 650 nascidos vivos, podendo acarretar outras complicações, como dificuldade na alimentação, fala, audição e interação social quando não corrigidas (MORAIS et al,.2020).

Ocorrem devido a defeitos na fusão anatômica dos processos faciais, entre a $4^{\underline{a}}$ e a I2 ${ }^{\underline{a}}$ semana da gestação (COSTAS; BORGES; ALMEIDA, 2020). Por volta da $7^{\text {a }}$ semana ocorre a fusão dos arcos branquiais e dos gomos faciais, neste momento se ocorrer o não fechamento acontece o aparecimento de uma fenda, sua localização e complexidade está relacionada a falha no processo do qual resultou ela (APPLETON, 2018).

É comprovada a relação de fatores genéticos para a ocorrência da FLP, sendo relacionada com a hereditariedade, porém na maioria dos casos já relatados ocorre a atuação em conjunto com fatores ambientais (COSTA et al., 2018), como a exposição da mãe a fumaça do tabaco, álcool, desnutrição, infeção viral, medicamentos e teratógenos no local de trabalho ou no domicílio no início da gravidez (COSTAS; BORGES; ALMEIDA, 2020).

Nos casos de origem genéticas os principais genes envolvidos as FLP não sindrômicas são Interferon Regulatory Factor (6IRF6), Bone Morphogenetic Protein 4 (BMP-4), Muscle Segment Homeobox I (MSXI), SATB Homeobox 2 (SATB2), T-box Transcription Factor (TBX22), Transforming Growth Factor Alfa (TGF-E), Transforming Growth Factor Beta (3TGF-T3), GREM-I, V-maf Musculoaponeurotic Fibrosarcoma Oncogene Homolog B (MAFB), ATP-Binding Cassette, Sub-family $\mathrm{A}_{4}\left(\mathrm{ABCA}_{4}\right)$ (PEREIRA, 2019).

Mesmo que a maioria dos casos de FLP sendo casos isolados, elas também podem ocorrer estando associadas a Síndromes, sendo mais constantemente encontradas nas Síndromes Van der Woude, Pierre Robin, de Stickler e velocardiofacial, com consequências a diversos sistemas podendo provocar malformações cardiovasculares, perturbações no neurodesenvolvimento, deficiência imunológica, baixa estatura, microcefalia e dimorfismo facial (COSTA et al., 2018, PEREIRA, 2019). 
Com bases em estudos epidemiológicos sobre FLP notou-se que apresenta incidência diferente para os tipos de etnias, havendo maior prevalência nas populações Asiáticas e Nativo-Americanas, seguida pela população Caucasiana e então a Africana. De acordo com pesquisas a prevalência pode também estar associada ao sexo, sendo que o sexo masculino está 2 vezes mais predisposto a desenvolver uma fissura labial, palatal ou associadas, já no sexo feminino a uma tendência a fendas que afetam apenas o palato. Isso se dá ao fato de que o processo de fusão do palato secundário, ocorre mais tarde no sexo feminino. Contudo, é relatado uma predominância mundial no sexo masculino de fissuras (APPLETON, 2018, PEREIRA, 2019).

O diagnóstico pré-natal das anomalias faciais fetais passou a acontecer após a inclusão da ultrassonografia na rotina propedêutica obstétrica, levando ao aconselhamento e conduta para melhor tratamento da criança, a fenda labial pode ser detectada no segundo trimestre de gestação, mas para conseguir o diagnóstico de fissuras de palato é mais complexa e requer recursos tecnológicos mais sofisticados como US tridimensional (SANTOS et al,2020, (SANTOS; OLIVEIRA, 2021)

\subsection{Classificação das Fissuras Labiopalatinas}

Como o lábio e palato primário têm origens embriológicas diferentes do palato secundário, as fendas podem ser subdivididas em fendas do lábio com ou sem fenda do palato e fendas do palato isoladas (PEREIRA, 2019). É importante diagnosticar corretamente o tipo da fissura para realizar um melhor planejamento e tratamento ideal. Sendo assim é importante que os sistemas de classificação das FLP busquem ter simplicidade, objetividade e clareza na descrição dos diferentes tipos de fissura (PRADO et al.2018).

A literatura apresenta diversas classificações que surgiram ao passar do tempo embasada em critérios morfológicos e embrionários. Conforme os critérios morfológicos, sobressaem as classificações anatómicas de Davis e Ritchie (1922), Brophy (1924), Veau (1931), Spina (1973) e LAHSHAL, e aos critérios embriológicos destaca-se a classificação de Kernahan e Stark (1958) (PEREIRA, 2019).

O sistema LASHAL separa a cavidade oral em 6 partes diferentes, sendo elas Lábio Direito (Right Lip), Rebordo Alveolar Direito (Left Alveolus), Palato Mole (Soft Palate), 
Palato Duro (Hard Palate), Rebordo Alveolar Esquerdo (Left Alveolus) e Lábio Esquerdo (Left Lip). A letra maiúscula significa a presença de uma fenda completa na zona onde está marcada, a fenda incompleta é simbolizada pela letra minúscula e a ausência de fenda por um ponto (APPLETON, 2018).

A classificação sugerida por Kernahan e Stark, em 1958, é uma das mais utilizadas, pois possibilita observar a estrutura anatómica envolvida, considerando o forame incisivo como ponto de referência embriológico. Como atualização de sua classificação em I97I, Kernahan apresentou o diagrama striped $\mathrm{Y}$, possibilitando uma melhor visualização para ela, onde compara a fenda com a letra "Y" (Figura I) (PEREIRA, 2019).

\section{Figura I - Diagrama de Striped Y}
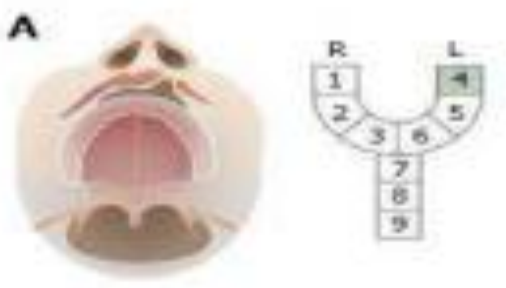

C
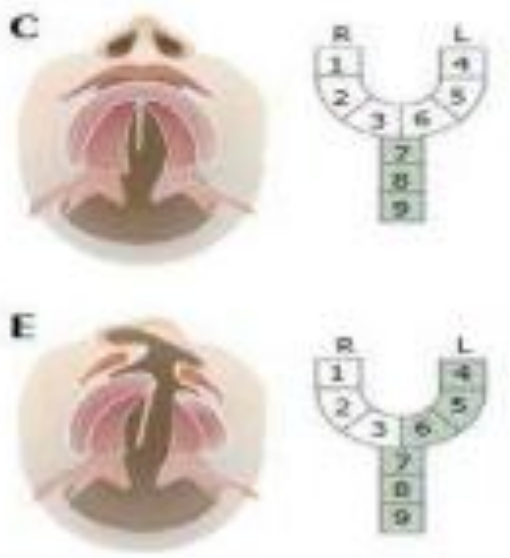

B
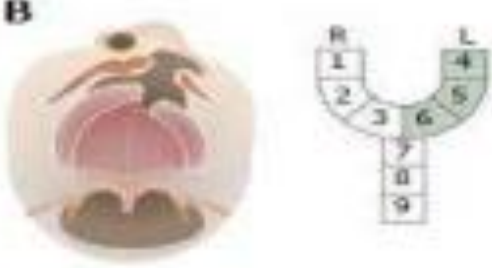

D
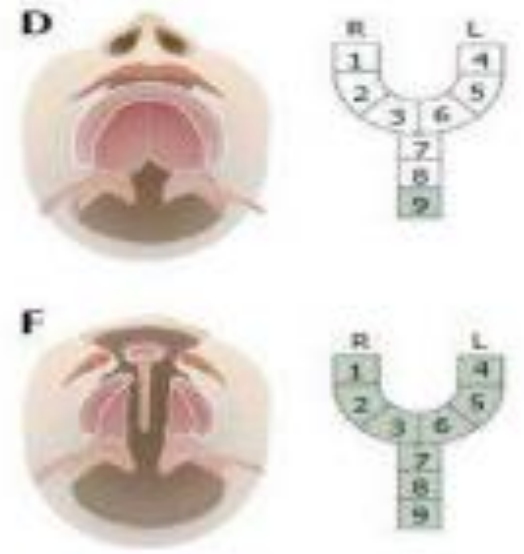

Fonte: PERREIRA (2019)

A classificação de Spina, que é a mais utilizada no Brasil, tem origem no desenvolvimento embriológico, e divide as fissuras em 4 grupos, sendo eles fissura préforame incisivo, transforame incisivo, pós-forame incisivo e fissuras raras da face, sendo que cada uma delas se subdividem em outras categorias por sua localização e extensão (PEREIRA, 2019):

- Fissura pré-forame incisiva: apenas labial, originada da falta de fusão dos processos maxilares com os processos nasais medianos. Se subdivide em unilateral, 
bilateral ou mediana e completa, quando alcança o alvéolo, ou incompleta, quando não há envolvimento do alvéolo.

- Fissura transforame incisivo: resulta da não fusão do mesênquima dos processos palatinos laterais do palato e do septo nasal. Envolve lábio, alvéolo e todo o palato. Pode ser subdividida em unilateral ou bilateral.

- Fissura pós-forame incisivo: são as fendas palatinas, resultado da não fusão dos processos palatinos entre si e com o septo nasal. Localizadas medialmente, pode afetar apenas a úvula, o palato mole, quando incompleta, ou alcançar o palato duro, completa. Não gera problemas estéticos, porém pode gera problemas para a alimentação, respiração e comunicação.

- Fissuras raras da face: abrange lábios, nariz, olhos e mandíbula (COSTA et al., 2018).

Conforme ilustrado na figura 2.

Figura 2 - Classificação de Spina

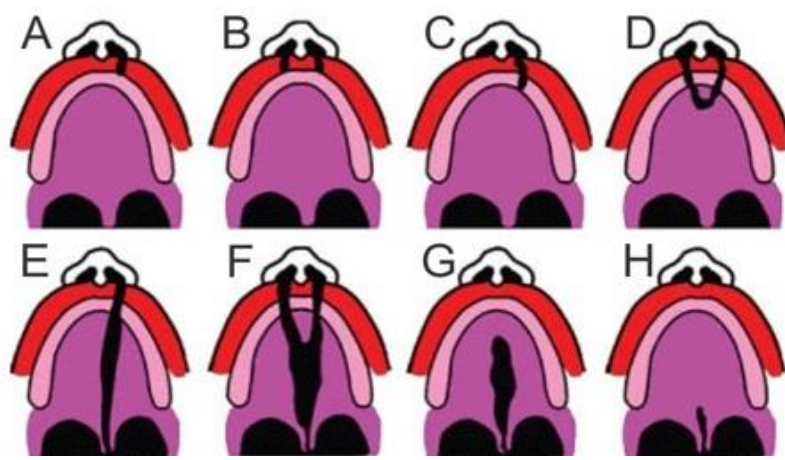
A - Fissura Labial Esquerda Pré-forame Incompleta
B - Fissura Labial Bilateral Pré-forame Incompleta
C - Fissura Labial Esquerda Pré-forame Completa
D - Fissura Labial Bilateral Pré-forame Completa
E - Fissura Labial Esquerda Transforame Completa
F - Fissura Labial Bilateral Transforame Completa
G - Fissura Palatina Pós-forame Completa
H - Fissura Palatina Pós-forame Incompleta

Fonte: COSTA, BORGES, ALMEIDA (2020)

\subsection{Manifestações Clínicas}

As disfunções funcionais e estéticas provocadas pelas FLP são complexas e podem acarretar manifestações clínicas e psicossociais secundárias, que afetam gravemente a vida dos pacientes. As fendas labiais isoladas provocam especialmente problemas estéticos, quando há envolvimento dos alvéolos pode também envolver problemas dentários, afetando assim também a função, já quando a associação do palato as manifestações clínicas são mais graves (SANTOS; OLIVEIRA, 202I). 


\subsection{Disfunções Alimentares}

Um dos principais problemas que acometem pacientes com FLP é para alimentação, principalmente no início quando ocorre a dificuldade da amamentação natural devido a lesão, porém o aleitamento materno oferece diversas benefícios para estes pacientes, já que quando a criança suga com uma força maior favorece o desenvolvimento da musculatura da face e aumenta a força dos movimentos executados com a língua, aprendendo a posicionar a língua de maneira correta, ganhando tônus e oclusão adequadas, afastando hábitos, como sucção de chupeta e digital (figura 3)(SANTOS et al,2020).

Figura 3 - Posição adequada para amamentação de bebês com fissuras

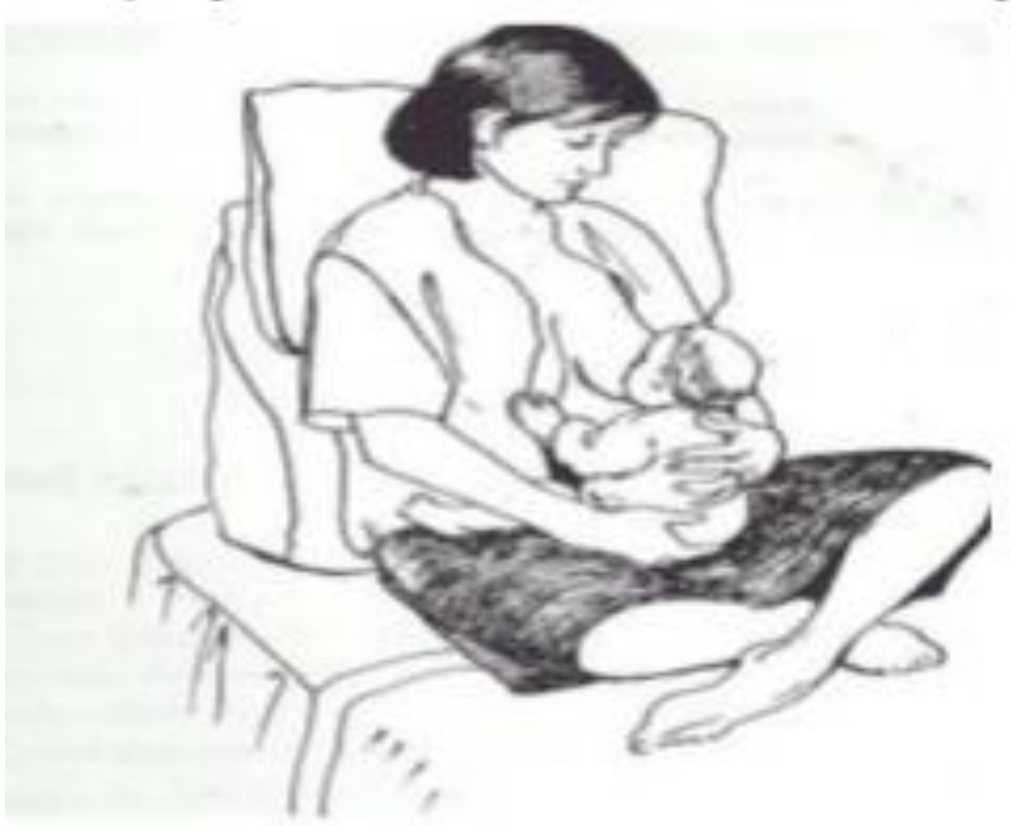

Fonte: SILVEIRA et al. (2020)

Os pacientes com lesões no palato têm dificuldade em criar pressão intraoral negativa suficiente para à sucção do leite, o que prejudica o estado nutricional do bebê, afetando assim seu peso e crescimento normal. Percebe-se também que ocorre regurgitação nasal pela comunicação entre a cavidade oral e nasal em que o leite é aspirado pelos pulmões. A deglutição de ar, fadiga, vômitos, engasgos e asfixias, típicos das fissuras palatinas podem também prejudicar a alimentação e nutrição do paciente (PEREIRA, 2019). 


\subsubsection{Distúrbio de Fala}

Outro problema que afeta os portadores de FLP é a fala, sendo um com as maiores complexidade, sendo necessário diversos tratamentos e acompanhamento para amenizar os danos (COSTA et al.,2021), geralmente associado a disfunção do mecanismo velofaríngeo, onde acontecem distúrbios articulatórios do desenvolvimento, distúrbios articulatórios compensatórios, distúrbios obrigatórios, como a hiper nasalidade, e adaptações compensatórias, que comprometem a clareza da fala (SANTOS; OLIVEIRA, 202I).

Essas alterações podem acarretar à respiração bucal, como o colapso da asa do nariz, desvios do septo nasal, hipertrofia dos cornetos, hipertrofia da adenoide e rinopatia alérgica, gerando danos nas estruturas dentárias, deficiência da fala e na saúde geral do paciente (COSTA et al.,2021).

\subsubsection{Disfunções Auditivas}

Pacientes com FLP tem maior chance de apresentarem casos de amigdalites e otites médias, que podem levar à perda de audição. A comunicação entre a cavidade oral com a nasofaringe possibilita que aconteçam refluxos de substâncias estranhas que podem obstruir a tuba auditiva, causando danos irreversíveis à audição (COSTA et al.,202I).

É relatado na literatura uma relação entre alterações no processamento auditivo central e as FLP, devido a casos de otite média, sendo importante a avaliação audiológica nesses pacientes para reconhecer estas alterações precocemente e diminuir as chances de problemas graves no futuro (CARLOS, 2020).

\subsubsection{Problemas Psicossociais em pacientes de Fissuras Labiopalatinas e nos cuidadores}

Pelo tratamento longo e complexo que a lesão ocasiona alterações emocionais e de comportamento como a ansiedade, intimidação e depressão, o que também é afetado pelo grau da deformação, que pode complicar a convívio social na infância pela aparência facial, como o desenvolvimento de amizades (PEREIRA, 2019). Os cuidadores das crianças com FLP também são afetados por esses problemas, o nascimento de um filho com uma malformação pode acarretar sentimentos conflitantes, como culpa, choque e preocupações com o futuro (SANTOS; OLIVEIRA, 202I). 
Esses sentimentos no paciente iniciar quando completa dois anos de idade, no período em que começa a ter noção que seu rosto é diferente e que seu aprendizado da fala é mais difícil, o segundo impacto ocorre quando ela inicia a se envolver com outras crianças nas creches ou maternais, essas ações causam como distúrbios primárias o isolamento espontâneo e a recusa em se comunicar e interagir. Na terceira fase ocorre por volta dos sete anos, quando começa a frequentar a escola, e assim ocorrem os apelidos ofensivos, que induzem de modo negativo o desenvolvimento intelectual da criança (COSTA et al.,2021).

Com isso os cuidadores devem ter apoio emocional e social para preparar a criança para se aceitar e encarar esse diagnóstico de fora tranquila e saudável. Preparando-a também para suportar as várias intervenções cirúrgicas e sua autoconfiança (PEREIRA, 2019), sendo assim, o apoio psicológico para o enfrentamento do estresse, da ansiedade e do medo é importante para o paciente e familiares (SANTOS; OLIVEIRA, 2021).

\subsubsection{Problemas Dentários}

Segundo a literatura a anomalia dentaria mais comum em pacientes com FLP são as agenesias dentárias, geralmente do lado comprometido pela fenda. Ocorre de forma diferente em cada dentição, na decídua e permanente, tendo um predomínio a presença de incisivos laterais supranumerários e fusionados na dentição decídua, sendo que a permanente é mais afetada por agenesia e microdontia (figura 4) (PEREIRA, 2019).

Podem ocorrer também dentes inclusos, anomalias de estrutura, como hipoplasia de esmalte, amelogénese imperfeita, dentinogénese imperfeita, entre outras, cáries, sendo com relação ao posicionamento dos dentes contíguos à fenda por uma dificuldade na higienização, no mesmo sentido é referente a doença periodontal (APPLETON, 2018).

Referente a alterações oclusais ocasionado pela FLP, pode se destacar mordidas cruzadas uni e bilaterais, mordidas abertas, classe III e overjet diminuído. Ocorre também os dentes neonatais e natais no local da fenda, incluindo principalmente os incisivos centrais maxilares, principalmente quando associadas a síndromes, que aparecem com mobilidade e sem a raiz formada, sendo indicado a sua extração (PEREIRA, 2019). 
Figura 4- Paciente fissurado que apresenta hipodontia e agenesias
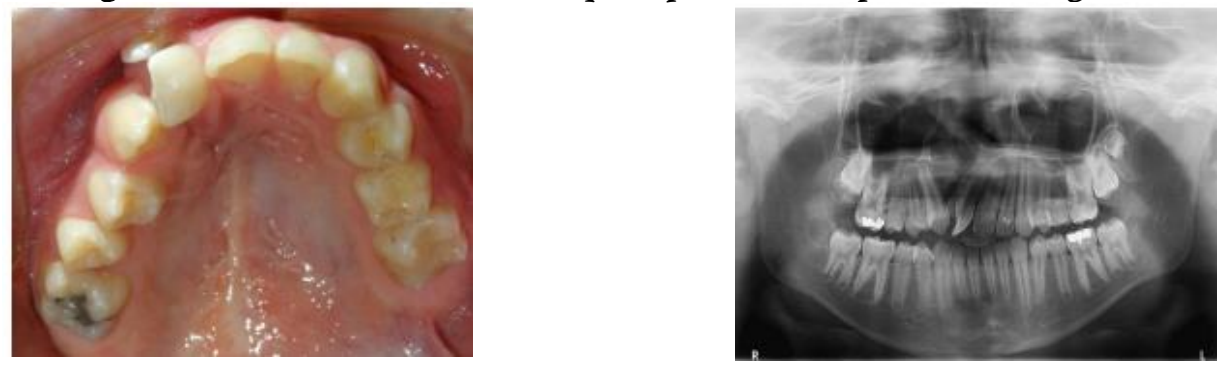

Fonte: LIMA, SAITO, SAITO (2019)

\subsection{Tratamento do paciente com Fissuras Labiopalatinas}

O tratamento das FLP deve ser realizado por uma equipe multidisciplinar, onde estão inclusos profissionais da pediatra, cirurgião bucomaxilofacial, ginecologista-obstetra, neonatologista, geneticista, cirurgião plástico, odontopediatra, fonoaudiólogo, ortodontista, protesista, psicólogo, nutricionista e clínico geral, entre outros, que devem trabalhar em harmonia para assim aumentar a qualidade de vida do paciente (SANTOS et al,2020, APPLETON, 2018).

O que definira qual será o protocolo cirúrgico adotado está principalmente associado às idades em que ocorrerá cada cirurgias, a técnica cirúrgica que será utilizada e a experiência clínica do profissional, o sucesso do tratamento também está relacionado com a maneira que será realizada o atendimento da equipe multidisciplinar e com como será o pós-operatório (PEREIRA, 2019).

O desenvolvimento de um protocolo geral para o tratamento dos pacientes com FLP tem sido um obstáculo nas pesquisas atualmente, porém é importante que o momento das cirurgias esteja alinhado ao crescimento da criança (PEREIRA, 20I9). Independente do protocolo realizado este deve respeitar os "5 A", sendo eles do inglês, Airway (Permeabilização das Vias Aéreas), Articulation (Articulação), Anterior Fistula Avoidance (prevenção de Fístula), Arch (Arcada) e Aestethics (Estética) (APPLETON, 2018).

No Brasil o protocolo utilizado em vários serviços especializados é a realização das cirurgias reparadoras inicialmente, sendo a queiloplastia realizada aos 3 meses de idade, e a palatoplastia aos 12 meses. Com aproximadamente 6 anos são realizadas as cirurgias secundarias para melhora estética, funcional ou correções de prováveis fistulas de palato, e se necessário na adolescência é realizada as correções nasais, como rinoseptoplastia, e a cirurgia ortognatica. Tratamento odontológicos para diminuir discrepância entre maxila e 
mandíbula e problemas dentários são feitos após a maturação óssea (SANTOS; OLIVEIRA, 2021).

\subsection{Queiloplastia}

A queiloplastia é a primeira cirurgia realizada, que é definida como a reconstrução naso-labial, e o melhor momento para sua realização sem risco anestésico é aos 3 meses de vida tendo a criança o peso mínimo de $4,5 \mathrm{~kg}$, Iomg/dl de hemoglobina e não ter malformação congênita associada. Esta cirurgia pode ser realizada até os 12 meses sem que ocorra efeitos prejudiciais ao crescimento maxilar (PEREIRA, 2019).

Tem como objetivos a reabilitação da parte funcional da musculatura orbicular dos lábios e tambem o reestabelecimento da estética. Sendo seu elemento mais importante reconstituição labial total envolvendo tecido cutâneo, mucosa e músculo (DI BERNARDO et al., 2017). Uma das técnicas mais utilizadas é a de Millard, que é descrita por Appleton (2018). como:

Esta técnica passa pelo encerramento da fenda em três planos distintos (cutâneo, muscular e mucoso) no qual se aproximam as margens da fenda excisionando o tecido hipoplásico, sendo o plano cutâneo encerrado em alongamento com plastia em $\mathrm{Z}$ alta. A questão primordial passa pela correta reconstrução do músculo orbicular da boca num esfíncter continuo e um alinhamento do bordo vermelho.

Demonstrada nas figuras 5 e 6 :

Figura 5- Técnica de Millard
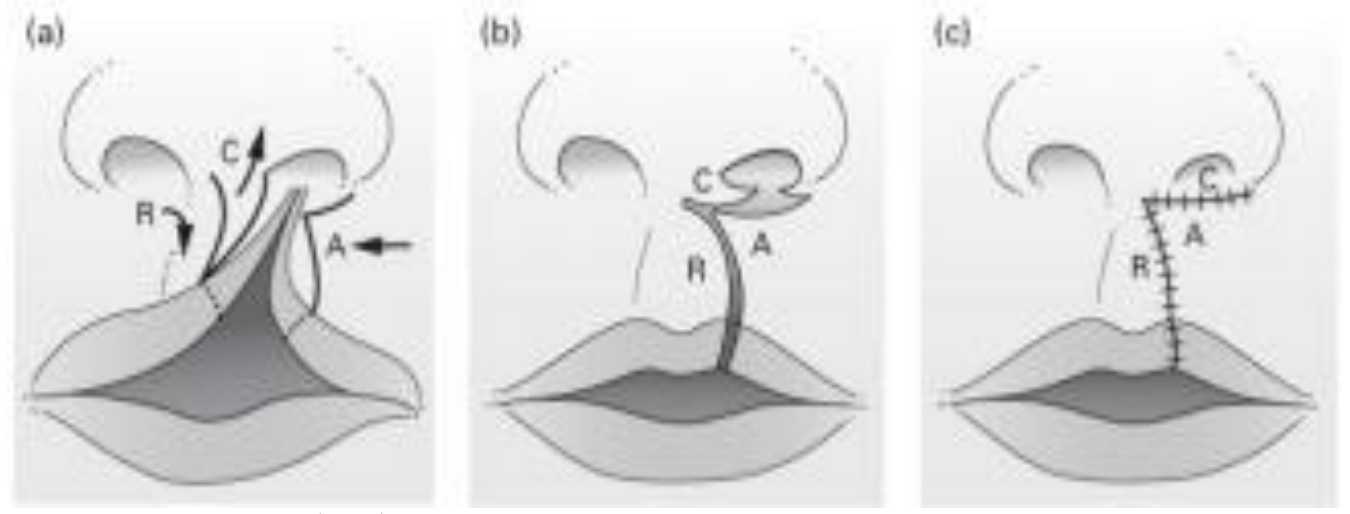

Fonte: APPLETON (2018) 
Figura 6 - Resultado da cirurgia de queiloplastia
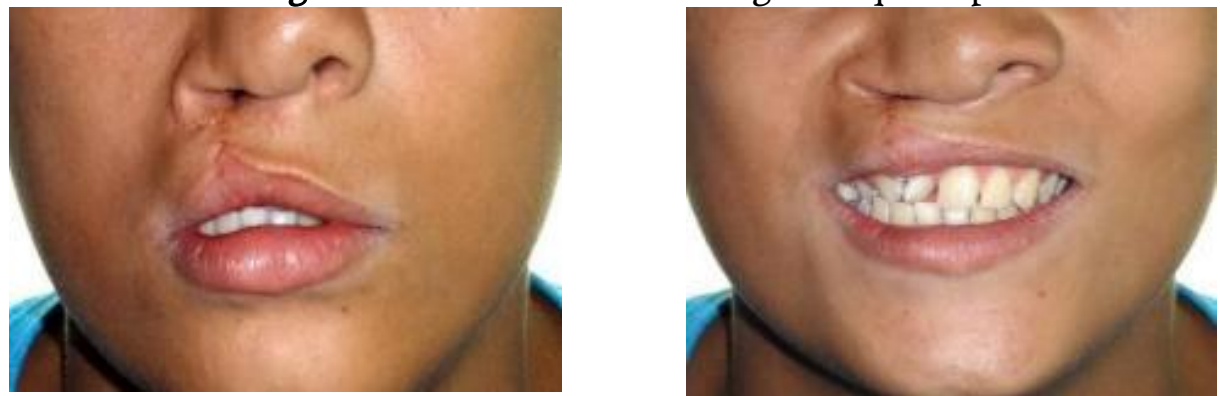

Fonte: LIMA, SAITO, SAITO (2019)

\subsubsection{Palatoplastia}

É a cirurgia voltada para a reconstrução do palato, deve ser executada entre os seis e dezoito meses para que o paciente consiga desenvolver uma normal pronuncia das palavras sem mecanismos compensatórios, se realizada tardiamente além da disfunção da fala, apresenta dificuldades alimentares maiores, principalmente com a introdução da alimentação mais consistente (PEREIRA, 2019).

Tem como principal objetivo a separação entre o espaço oral e a nasofaringe, necessitando a mobilização do retalho por planos, pela inserção muscular anormal, eles devem ser desinseridos nas margens da fenda e reconstruídos na linha media, sendo o palato mole encerrado no plano nasal, muscular e mucoso e o palato duro no plano mucoso nasal e oral (APPLETON, 2018).

A cirurgia pode ser realizada por várias técnicas, sendo a mais utilizada a Técnica de von Langenbeck, realizada em um tempo cirúrgico, onde se realizam a união retalhos mucoperiostais iniciando por extensas incisões relaxantes laterais, assim o encerramento é realizado por camadas, sendo o assoalho nasal, tecido muscular e forro oral (Figura 7 e 8) (DI BERNARDO et al., 2017).

Figura 7 - palatoplastia pela técnica de Von Langenbeck
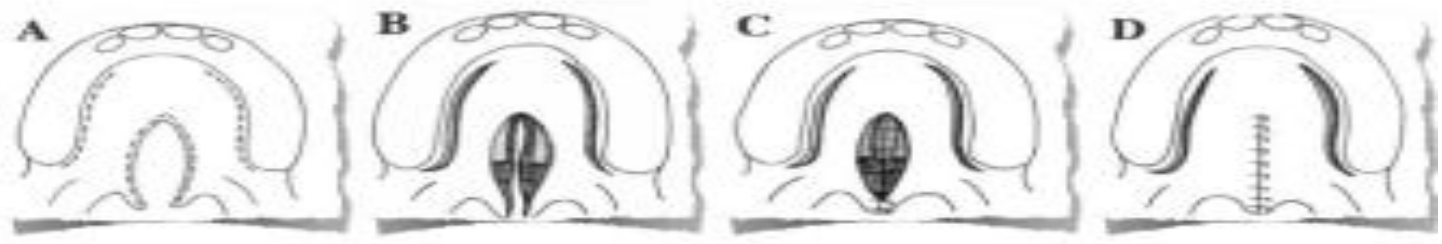

Fonte: SATO; SILVA; MOREIRA (2016) 
Figura 8 - Resultado da cirurgia de palatoplastia

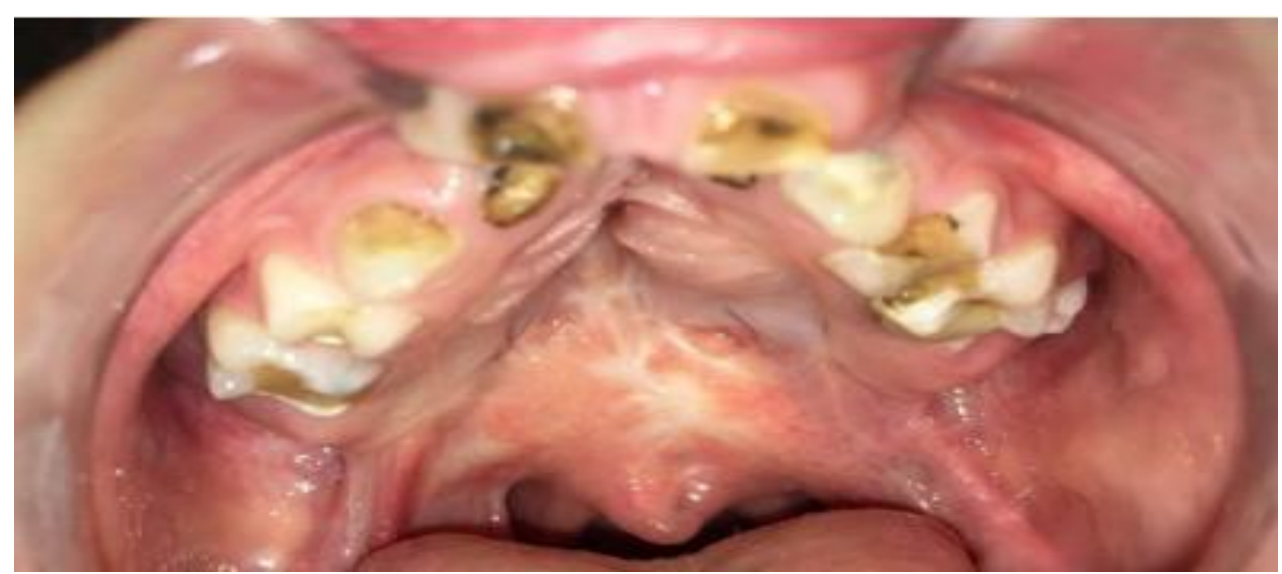

Fonte: SCHILLING (2019)

2.4.3 Ortopedia Maxilar pré-cirúrgica

Algumas crianças realizam a ortopedia pré-cirúrgica antes da queiloplastia o que permite melhora da posição dos segmentos alveolares superiores e na estética do lábio e nariz, reduzindo a amplitude da fenda e facilitando a cirurgia, a deglutição, respiração e tem efeitos psicológicos positivos nos pais (PEREIRA, 2019).

2.4.3.I Remodelação Nasoalveolar Pré-Cirúrgica

Se dá pela a utilização de dispositivos para que ocorra a aproximação dos segmentos maxilares e alveolares através do processo de crescimento da face e do crânio, age pela sucção, gerando uma restruturação gradativo dos tecidos moles e ósseos. Leva um componente nasal ajustável, que atua não só no nariz, mas também pela estimulação muscular do lábio, realizando uma aproximação das bordas da fenda (Figura 9) (APPLETON, 2018).

Figura 9 - Exemplo de antes e depois da Remodelação Nasoalveolar Pré-Cirúrgica
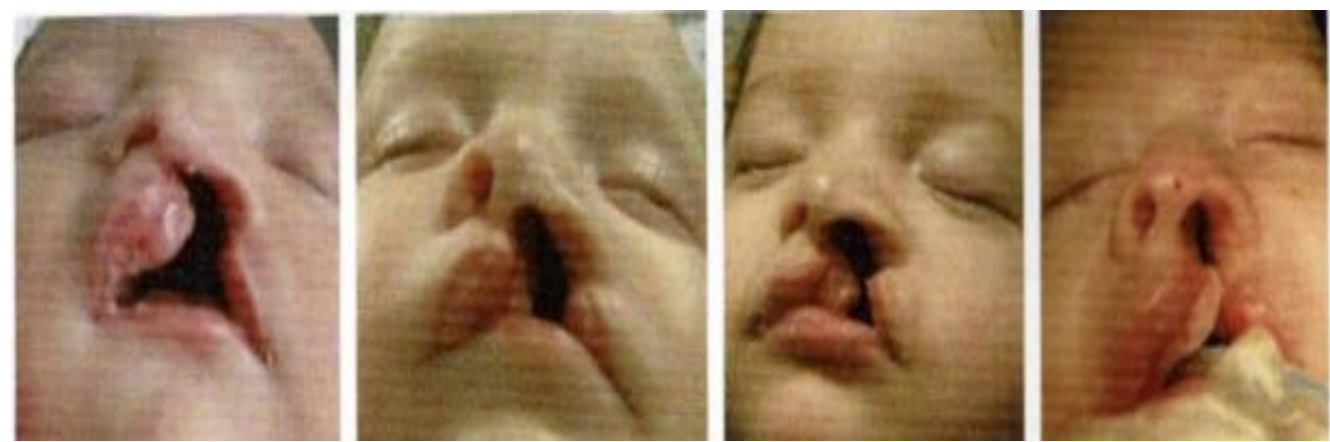

Fonte: APPLETON (2018) 


\subsubsection{Ortho Aligner NAM}

Um projeto da faculdade de Odontologia UFMG que realiza o tratamento précirúrgico de FLP utilizando uma sequência de placas. É realizado através da moldagem do paciente, feito o planejamento virtual, realizada a confecção das placas, que serão trocadas semanalmente na boca do paciente. $\mathrm{O}$ tratamento deve começar nos primeiros dias de vida do bebê até o sexto mês, quando iniciam a erupção dos primeiros dentes e visto como momento ideal para ser realizada a cirurgia. Como benefícios pode-se destacar uma cirurgia menos traumática, melhora na amamentação, melhora na sucção, auxilia na respiração, ajuda na higienização e fechamento da fenda (COSTAS; BORGES; ALMEIDA, 2020).

\subsubsection{Quad-Helix Modificado}

É um aparelho ortodôntico usado na arcada superior com a finalidade de gerar uma expansão maxilar lenta, produzindo uma menor resistência ao redor das estruturas perimaxilares, gerando uma maior formação de osso na sutura palatina. A expansão ocorre com por forças aplicadas no complexo dentoalveolar, comprimindo os ligamentos periodontais, deslocando os processos alveolares e expandindo a sutura palatina (Figura ro) (APPLETON, 2018).

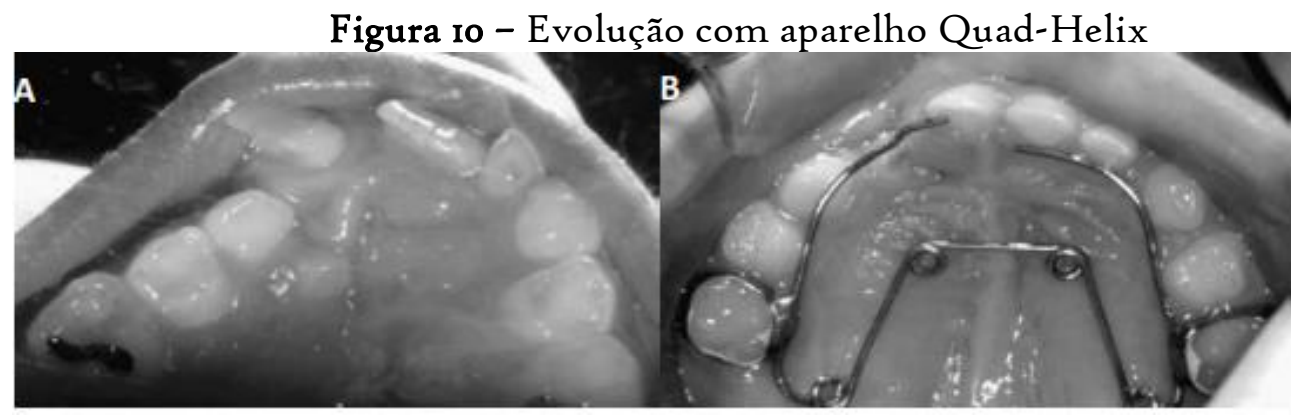

Fonte: CARVALHO (2018)

\subsubsection{Enxerto Ósseo Alveolar}

O enxerto ósseo é utilizado para pacientes de fissuras com origem no palato primário, isto é, fissuras com envolvimento do rebordo alveolar, essa malformação não é normalmente corrigida na cirurgia inicial, é realizada após as cirurgias reparadoras primarias. Esses enxertos aderem as porções alveolares e ajudam na prevenção da 
degradação e a constrição do arco, além de possibilitar suporte ósseo para os dentes próximos à fissura e para os que irão erupcionar na área da lesão (Figura II) (DI BERNARDO et al., 2017).

Figura II - Volume ósseo e tecido periodontal antes e depois de enxerto ósseo
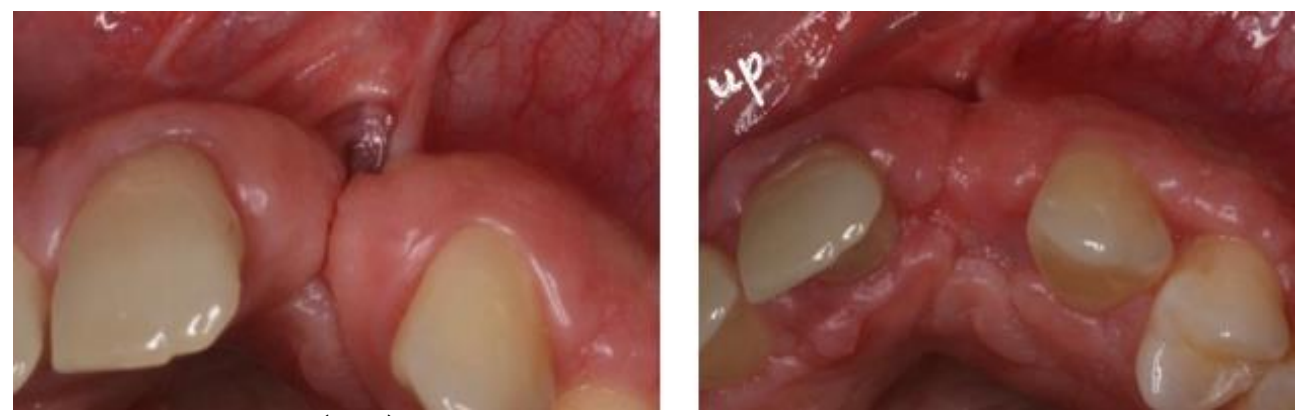

Fonte: APPLETON (2018)

É possível pela capacidade do tecido ósseo de se regenerar completamente no local onde é depositado. Atualmente estão disponíveis vários tipos de materiais para realização dos enxertos, estudos mostram resultados positivos com enxertos autógenos (da crista ilíaca do próprio paciente), Bone Morphogenetic Protein (BMPs) e Recombinant Human Protein

(RHP). É indicado enxerto nas fendas maiores que $2 \mathrm{~mm}$, se forem maiores de $2 \mathrm{~cm}$, é necessário recorrer a enxertos microvascularizados do fêmur. A desvantagens do enxerto é a chance de ocorrer a rejeição (APPLETON, 2018).

É utilizado de acordo com o estágio de desenvolvimento dentário, podendo ser enxerto alveolar primário, realizado durante o primeiro estágio da dentição, forma uma ponte óssea transversalmente ao defeito, o que não garante que a fístula será unida ou irá acontecer a formação adequada de osso (COSTA et al., 2018).

O enxerto secundário, que ocorre na fase da dentição mista, tem o propósito de restaurar o rebordo alveolar, realizar o fechamento da comunicação oro-nasal e estabilizar os segmentos maxilares, gerando o suporte ósseo para os dentes adjacentes à fissura, diminuindo os problemas de crescimento da maxila, auxiliando a correta erupção dos dentes e em seguida para movimentos ortodônticos e implantes (COSTA et al., 2018).

Já o enxerto ósseo na dentição permanente, também chamado de tardio ou terciário, tem uma taxa de sucesso reduzida, apresentando problemas de reabsorção cervical, não 
resolvendo os problemas de perda óssea dos dentes adjacentes a fissura (COSTA et al., 2018).

\subsubsection{Tratamento Cirúrgico da Disfunção Velofaríngea}

O anel velofaríngeo é constituída pelo palato mole, paredes laterais e parede posterior da faringe, e tem como função principal se manter aberto enquanto ocorre a respiração nasal, se fechar levemente ou não durante a produção dos fonemas nasais e se obstruir inteiramente durante a produção dos demais fonemas, assim como na deglutição, vômito, assobio e sopro (LIMA, 2019).

Quando não ocorre esse fechamento corretamente é chamado de Disfunção Velofaríngea, que pode ser devido a alteração estrutural, ou seja, falta de tecido no palato mole, sendo denominada insuficiência velofaríngea, tambem podem ser causadas por alterações neuromusculares, sendo chamada de incompetência velofaríngea, e por último pode ocorrer apenas por um erro no fechamento velofaríngeo, sendo denominada de erro de aprendizagem (FERREIRA, 2018).

A faringoplastia tem como proposito a correção da hiper nasalidade e do escape de ar nasal, melhorando assim a fala, equilibrando o estado de pressão intraoral e fluxo aéreo oral proporcionando uma melhor pronuncia dos fonemas, já para correção dos distúrbios articulares é necessária uma terapia fonoarticulatória (LIMA, 2019).

Existem 5 grupos de técnicas para a realização da cirurgia, sendo eles o aumento da parede posterior da faringe, a mobilização dos músculos levantadores do palato, a retroposição do palato (push-back), com retalhos faríngeos, e a esfincterplastia. A técnica que sera utilizada depende de como é a disfunção velofaríngea (LIMA, 2019).

\subsubsection{Cirurgia Ortognatica}

A cirurgia ortognatica é indicada para pacientes que têm má-formação envolvendo os ossos da face e os dentes, com o intuito de restabelecer a equilíbrio anatômica da face, assim quando o caso não se resolver apenas com uso de aparelhos ortodônticos e ortopédicos, quando a malformação ocorre no tamanho dos ossos do esqueleto e não apenas no posicionamento dos dentes, é necessária está cirurgia (figura I2) (LIMA, 2019). Sendo evidenciado na literatura que pacientes com FLP geralmente dispõe de hipoplasia 
anteroposterior de maxila e de má-oclusão classe III de Angle, resultando em um perfil côncavo (BARRETO et al., 2017).

Pela análise cefalométrica, realizada desde os 5 anos de idade do paciente, pode-se supor se o crescimento craniofacial será ou não favorável para ser realizado o tratamento. A melhor idade para fazer a cirurgia corresponde ao final do crescimento, sendo no sexo masculino por volta dos I7-18 anos e no feminino aos is anos (APPLETON, 2018).

O planejamento cirúrgico obedece aos passos convencionais similares com o de pacientes sem fissuras. Se com o desenvolvimento, o defeito mandibular dos pacientes com fissuras completas for destacado, se torna essencial a osteotomia basilar da mandíbula para avanço do mento Com é realizada após as cirurgias primárias e ao enxerto ósseo a presença de fibroses, que podem dificultar o avanço maxilar, fazendo necessário, a execução do recuo mandibular, ainda se este não estiver planejado durante o pré-operatório (BARRETO et al., 2017).

Figura 12 - Pré-operatório e Pós-operatório de ortognatica de paciente com FLP
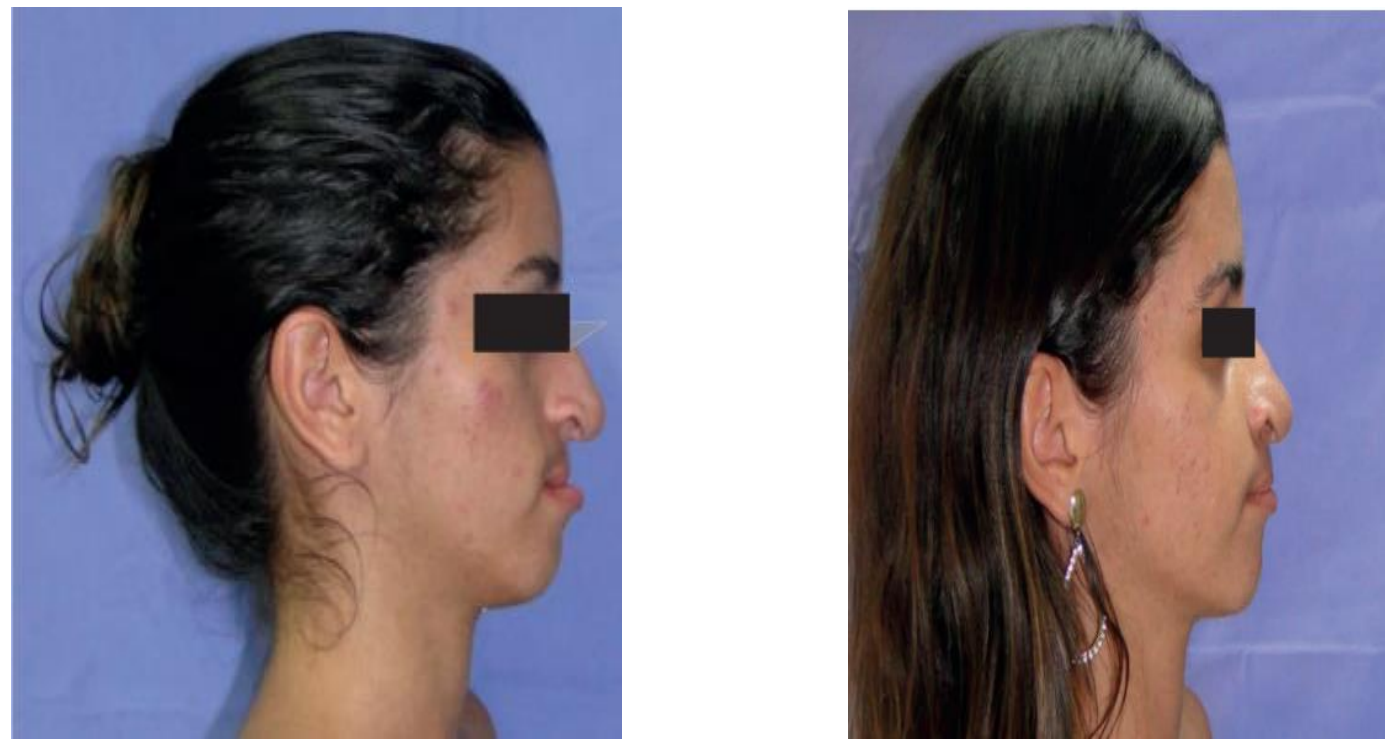

Fonte: Barreto, Santos, Carvalho, Souza, Pontes, Azevedo

Durante o pós-operatório apresenta dor, inflamação, disfagia, hemorragia, mobilidade reduzida, entre outros sintomas., é recomendado alimentação restrita a líquidos durante os primeiros dias, crioterapia, é receitado tratamento com AINES se houver dor (anti-inflamatórios não-esteroides), bochechos de Clorexidina e incentivo para higienização oral Atraumática (APPLETON, 2018). 


\subsubsection{Tratamentos secundários}

\subsubsection{Fonoaudiologia}

A fonoaudiologia deve ser iniciada ainda na maternidade em pacientes de FLP, realizado ainda na maternidade, pois a criança com fissura apresentará alterações na deglutição, sucção e respiração. São diversas as alterações que podem ocorrer na fala pela presença de fissuras, desde uma leve distorção de algum fonema, causada por deformidade dento facial até o desenvolvimento de hiper nasalidade e de mecanismos compensatórios. Grande parte dessas alterações está relacionada com a disfunção velofaríngea (LIMA, 2019).

Após a realização das cirurgias necessárias, como ortognatica e a correção da insuficiência velofaríngea, o fonoaudiólogo auxilia na recuperação das funções estomatognáticas, se estas não tenham se corrigido espontaneamente. O fonoaudiólogo pode trabalhar a parte muscular de duas maneiras a terapia miofuncional e a mioterapia. Levando assim a correção de possíveis complicações de comunicação (LIMA, 2019).

\subsubsection{Rinoplastia}

Geralmente as FLP acarretam desarmonias no nariz, causando problemas estéticos, funcionais e psicológicos, que podem afetar muito a vida do paciente. A cirurgia de rinoplastia nestes pacientes é realizado da mesma maneira e com as mesmas técnicas usadas em uma rinoplastia estética (LIMA, 2019).

O nariz dos pacientes de FLP tem em comum cinco principais características. Sendo a primeira que a columela aparenta mais curta no lado fissurado, com sua base inclinada desviada para o lado normal. A segunda característica se dá pela cruz lateral da cartilagem lateral ter uma posição inferior quando equiparado ao lado normal, aparentando uma letra "S". A terceira é que o domus do lado que houver a fissura é assimétrico e mais baixo. A quarta característica se dá pelas narinas do lado da fissura estarem de forma quase horizontal e retroposicionado. Na última característica é que a parte caudal do septo e da espinha nasal anterior são inclinados para o lado fissurado (LIMA, 2019). 


\subsubsection{Implantodontia}

Há evidência científica de que os implantes em pacientes portadores de fendas bilaterais apresentem maiores dificuldades do que os com fendas unilaterais, em razão a menor taxa de sucesso nos enxertos ósseos bilaterais. Pode também ser utilizado os implantes zigomáticos quando houver insuficiência óssea na área da fenda, apesar de ser uma opção mais invasiva. Sendo assim o uso de implantes para a reabilitação destes pacientes é uma possibilidade segura que demonstra resultados eficazes (APPLETON, 2018).

\subsubsection{Próteses}

Como opção para os problemas de agenesias dentárias também pode ser empregado a realização de uma Prótese Parcial Fixa. A maior intercorrência para esta reabilitação se dá pela adaptação do pôntico ao rebordo desdentado, visto que geralmente este ter uma alta perda óssea e de tecido periodontal nesta região (figura 13) (APPLETON, 2018).

Figura 13 - Preparo e prótese parcial fixa aplicada
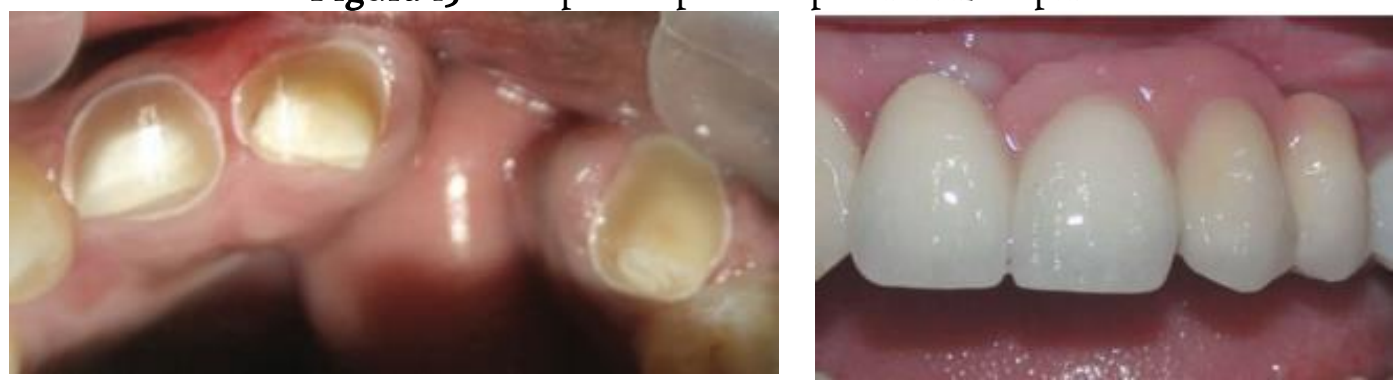

Fonte: APPLETON (2018)

Assim como a Prótese Parcial Removível (PPR) também pode ser apontada como opção para a reabilitação oral de portadores de FLP, apesar de não ser adequada para manter os tecidos. Pacientes com FLP geralmente apresentam casos de classe IV de Kennedy, em virtude das agenesias dos incisivos laterais, em sua maioria não está relacionada a uma zona desdentada muito grande, tendo um bom suporte dentário, o que faz com que se opte por uma prótese esquelética dento-suportada. Já em casos onde a agenesia de toda a região anterior pode se escolher as próteses dento-muco-suportadas, mesmo que esteja em decadência seu uso por causa do sucesso dos implantes, a PPR 
apresenta vantagens como um baixo custo e uma maior facilidade de manutenção (APPLETON, 2018).

\subsection{Centros de reabilitação de Anomalias Craniofaciais no Brasil}

No ano de 1993 ocorreu a introdução de procedimentos para correção de FLP e realização de implante dentário osseointegrado na tabela do Sistema de Informações Hospitalares do SUS, sendo este o primeiro passo do sistema para o tratamento destes pacientes, sendo publicada em 1994 a Portaria no 62, estabelecendo normas para o cadastramento de serviços de reabilitação da FLP (ALMEIDA; CHAVES, 2019).

Atualmente no Brasil encontram-se 29 centros de atendimento às Anomalias Craniofaciais, onde as FLP se destacam por ser uma das anomalias mais encontradas (SANTOS et al,2020). Dentre estes se destaca o Hospital de Reabilitação de Anomalias Craniofaciais (HRAC-USP), também conhecido como "Centrinho", que foi precursor no tratamento de FLP no Brasil, sendo inteiramente destinado ao atendimento de usuários do SUS (HRAC-USP, 202I).

Nasceu em 1967 como um Centro de Estudos Interdepartamental dentro da Faculdade de Odontologia de Bauru da Universidade de São Paulo (FOB-USP), que fazia pesquisa e oferecia atendimento à população, nomeado como Centro de Pesquisa e Reabilitação de Lesões Lábio-Palatais, mas com passar dos anos e as mudanças em sua estrutura em 1998 recebeu sua nova denominação de HRAC-USP pela ampliação do seu campo de atividade (HRAC-USP, 2021).

Atualmente é reconhecida nacionalmente e internacionalmente como centro referência no atendimento de pacientes com FLP, anomalias craniofaciais congênitas e deficiência auditiva. Com uma equipe multidisciplinar, altamente qualificada, oferece atendimento absoluto e humanizado aos pacientes (HRAC-USP, 202I).

No Estado do Mato Grosso, existe o Serviço de Reabilitação de Fissuras Labiopalatinas, inserido no Hospital Geral, que é um hospital referência no estado em patologias neurológicas, cardiorrespiratórias, malformações congênitas e craniofaciais, e maternidade, que atende todo o estado (FREITAS et al.,202I).

Este serviço constitui em um núcleo multiprofissional voltado aos cuidados, a integralidade e reabilitação do indivíduo com fissura FLP, tendo profissionais de áreas 
variadas como médicos pediatras, otorrinolaringologistas, cirurgiões plásticos, psicólogos, fonoaudiólogos, nutricionistas, fisioterapeutas, odontopediatras, cirurgiões bucomaxilofaciais e ortodontistas (FREITAS et al.,2021).

São ofertados aos pacientes de FLP serviços de tratamento preventivo e restaurador, com intuito de favorecer a saúde bucal, e restabelece-la antes da correção cirúrgica e a conservando no pós-operatório pelas ações educativas com responsáveis e motivacionais e preventivas aos pacientes para que adquiram capacidade de realizar a própria higiene por meio da técnica apropriada, além do uso de flúor e na orientação de uma dieta adequada (FREITAS et al.,2021).

\section{CONSIDERAÇÕES FINAIS}

Com isso este trabalho elucidou sobre a classificação das fissuras e a importância das cirurgias para correção das FLP, já que esta má formação pode desenvolver vários problemas no futuro dos pacientes sendo eles não apenas funcionais e estéticos como também psicológicos, podendo também afetar a vida dos familiares.

Demonstrando que a realização destas cirurgias traz diversos benefícios para a vida do paciente, como a melhora da amamentação natural quando recém-nascido e posteriormente na alimentação, no aspecto psicológico para o paciente e família, melhora na fonação do paciente entre outros, enfim trazendo uma maior qualidade de vida para este.

Portanto é de extrema importância que os familiares de portadores de FLP busquem realizar as cirurgias para correção o quanto antes para que assim consiga ser realizado o acompanhamento multidisciplinar do paciente durante toda sua vida, gerando um tratamento satisfatório.

\section{REFERÊNCIAS}

AlMEIDA, Ana Maria Freire de Lima; CHAVES, Sônia Cristina Lima. Avaliação da implantação da atenção à pessoa com fissura labiopalatina em um centro de reabilitação brasileiro. Cadernos Saúde Coletiva, [S.L.], v. 27, n. I, p. 73-85, mar. 2019. FapUNIFESP (SciELO). http://dx.doi.org/10.1590/1414-462x201900o10365. Disponível em: 
https://www.scielo.br/pdf/cadsc/v27nI/I4I4-462X-cadsc-27-I-73.pdf. Acesso em: 17 mar. 2021.

APPLETON, Tomás Mourato Vermelho Mega. Fendas lábio-palatinas. 2018. Tese de Doutorado. Disponível em: http://comum.rcaap.pt/handle/ro400.26/23515. Acesso em 25 mar. 202I

BARRETO, Lucas Silva et al. Cirurgia Ortognática em paciente com fissura labiopalatina: Relato de caso. Revista de Ciências Médicas e Biológicas, v. I6, n. I, p. IIO-II5, 2017. Disponível em: https://periodicos.ufba.br/index.php/cmbio/article/view/17366. Acesso em 20 abr. 2021.

CARLOS, Priscila. ALTERAÇÕES NO PROCESSAMENTO AUDITIVO (CENTRAL) EM CRIANÇAS COM FISSURA LABIOPALATINA: revisão sistemática. 2020. 17 f. TCC (Graduação) - Curso de Fonoaudiologia, Universidade Cesumar Unicesumar, Maringá, 2020. Disponível em: http://rdu.unicesumar.edu.br/bitstream/123456789/7428/I/CARLOS\%2c\%2oPRISCILA.p df. Acesso em: 29 mar. 2021.

CARVAlHO, António Maria Pimentel dos Santos Lopo de. Ortopedia neonatal, ortodontia e tratamento multidisciplinar de lábio leporino e fenda palatina. 2018. Tese de Doutorado. em: http://comum.rcaap.pt/bitstream/ro400.26/25544/I/Carvalho_Ant\%c3\%b3nio_Maria_Pim entel_dos_Santos_Lopo_de.pdf. Acesso em 3I de maio de 202I.

COSTA, Laura Hermínia et al. FISSURA LABIOPALATINA: REVISÃO LITERÁRIA. REVISTA SAÚDE MULTIDISCIPLINAR, v. 9, n. I, 2021. Disponível em: http://revistas.famp.edu.br/revistasaudemultidisciplinar/article/view/I72. Acesso em I6 mar. 202I

COSTA, Naiara Ferreira; BORGES, Adlla Liss Lopes; ALMEIDA, Severina Alves de. FISSURAS PALATINAS, INOVAÇÕES E NOVOS MEIOS DE TRATAMENTO: um estudo introdutório. Facit Business And Technology Journal, [S.I], v. 2, n. I4, p. I29I4I, 2020. Disponível em: FISSURAS PALATINAS, INOVAÇÕES E NOVOS MEIOS DE TRATAMENTO: UM ESTUDO INTRODUTÓRIO | COSTA | Facit Business and Technology Journal (websiteseguro.com). Acesso em: 17 mar. 2021. 
Costa, Tadji Liveira et al. Fissura labiopalatina e ortodontia: revisão de literatura. Rev Cien VirviRamos. v.6, n. I, p. 46-55, 2018. Disponível em: https://www.faculdadefatima.com.br/imagens/paginas/revista-cienti-fica-virvi-ramosvol-o6-2018-I-v03-pdf2076436529.pdf \#page=46. Acesso em I5 abr. 2021.

COSTA, Verônica Cristine Rodrigues et al. Aspectos etiológicos e clínicos das fissuras labiopalatinas. Revista de Medicina e Saúde de Brasília, [S. L.], v. 2, n. 7, p. 258-268, ago. 2018.

https://edisciplinas.usp.br/pluginfile.php/5588447/mod_resource/content/r/Costa\%2oet \%20al.,\%202018\%20-

\%20Aspectos\%2oetiol\% $\mathrm{C}_{3} \% \mathrm{~B} 3$ gicos\%2oe\%2ocl\%C3\%ADnicos\%2odas\%2ofissuras\%2olabio palatinas.pdf. Acesso em: I7 mar. 202I.

DE FREITAS, Thyago Munoz et al. Efetividade do tratamento odontológico preventivo em pacientes com fissuras labiopalatinas no ambulatório de odontopediatria do hospital geral de Cuiabá-MT. Disponível em: https://pubsaude.com.br/revista/efetividade-dotratamento-odontologico-preventivo-em-pacientes-com-fissuras-labiopalatinas-noambulatorio-de-odontopediatria-do-hospital-geral-de-cuiaba-mt/. Acesso em: 12 mar. 202I. DI BERNARDO, Bárbara et al. FISSURAS LÁBIO-PALATINAS: Tipos de Tratamento-Revisão de Literatura. Conversas Interdisciplinares, v. 13, n. 3, 2017. Disponível em: http://www.periodicos.ulbra.br/index.php/ci/article/view/3984. Acesso em I5 abr. 2021.

DO PRADO, Jônatas Peireira et al. Desmistificando as Fissuras Labiopalatinas. ID on line REVISTA DE PSICOLOGIA, v. I2, n. 42, p. 229-24I, 2018. Disponível em: https://idonline.emnuvens.com.br/id/article/view/I433. Acesso em 29 mar. 202I.

FERREIRA, Gabriela Zuin. Programa de fonoterapia intensiva em pacientes com fissura labiopalatina. 2018. Tese de Doutorado. Universidade de São Paulo. Disponível em: https://www.teses.usp.br/teses/disponiveis/25/25143/tde-15052019-

191152/publico/GabrielaZuinFerreira.pdf. Acesso em 20 abr. 2021.

História. Bauru: HRAC-USP. Disponível em: http://hrac.usp.br/institucional/historia/. Acesso em or abr. 202I.

LIMA, Marcelo Capistana de. Hipodontia associada à fissura unilateral de lábio e palato em paciente não sindrômico: relato de caso. Revista de ciências da saúde da Amazônia, 
2019 .

Disponível

em:

http://repositorioinstitucional.uea.edu.br/bitstream/riuea/2716/I/Hipodontia\%20associad a\%20\%c3\%a0\%2ofissura\%20unilateral\%20de\%201\%c3\%arbio\%20e\%20palato\%20em\%20pacie nte\%20n\%c3\%a30\%20sindr\%c3\%b4mico\%20relato\%20de\%20caso.pdf. Acesso em 30 maio 202I.

MORAIS, Margarida Milena Viana et al. Assistência ao portador da má formação de fissura labiopalatina. Brazilian Journal of Health Review, v. 3, n. I, p. 209-219, 2020. Disponível em: 339215475_Assistencia_ao_portador_da_ma_formacao_de_fissura_labiopalatina. Acesso em: 17 de mar. 2021.

PEREIRA, Ana Rita Costa. Problemas orofaciais em pacientes com fendas lábiopalatinas. 2019. 56 f. Dissertação (Mestrado) - Curso de Odontologia, Instituto Universitário de Ciências da Saúde, $[\mathrm{S} . \mathrm{I}]$, 2019. Disponível em: https://repositorio.cespu.pt/bitstream/handle/20.500.II8I6/3184/MIMD_RE_2258I_AnaPer eira_Relat\%C3\%B3rioFinal.pdf?sequence $=\mathrm{I} \&$ is Allowed=y. Acesso em: 29 mar. 2021.

SANTOS, Eliane Alves Motta Cabello dos; OLIVEIRA, Thais Marchini de. Conhecimentos atuais em Fissuras Labiopalatinas: uma revisão narrativa. Revista Eletrônica Acervo Saúde, [S.L.], v. 13, n. 2, p. I-8, 2 fev. 2021. Revista Eletronica Acervo Saude. http://dx.doi.org/ro.25248/reas.e5870.2021. Disponível em: https://acervomais.com.br/index.php/saude/article/view/5870. Acesso em: I7 mar. 202I. SANTOS, João Vitor do Nascimento et al. FISSURA LABIOPALATINA:: estudo do papel do profissional de saúde na diminuição dos danos ao paciente. Revista Ciências e Odontologia, [S.I], v. I, n. 4, p. 48-55, mar. 2020. Disponível em: https://sumarios.org/revista/revista-ci\%C3\%AAncias-e-odontologia. Acesso em: 17 mar. 2021.

SATO, Fábio Ricardo Loureiro; DA SILVA, Magno Liberato; MOREIRA, Roger William Fernandes. Evaluation of two palatoplasty techniques in patients with cleft palate. Disponível em: https://www.researchgate.net/profile/MagnoLiberato/publication/310666407_Evaluation_of_two_palatoplasty_techniques_in_patients_ with_cleft_palate/links/6063e8oc9285icd8ce7aeo25/Evaluation-of-two-palatoplastytechniques-in-patients-with-cleft-palate.pdf. Acesso em is abr. 202I. 
SCHILLING, Gabriela Ribeiro. Associação entre alterações de fala e dento-oclusais e a época das cirurgias plásticas primárias em crianças com fissura labiopalatina. 2019. Disponível em: https://repositorio.ufcspa.edu.br/jspui/bitstream/123456789/1148/1/\%5BDISSERTA\% ${ }_{3}$ $\% 87 \% \mathrm{C}_{3} \% 83 \mathrm{O} \% 5 \mathrm{D} \% 20 \mathrm{Sch}$ illing\%2C\%20Gabriela\%2oRibeiro. Acesso em or junho de 2021. SCHÖNARDIE, Marina Silveira et al. Relação entre o desenvolvimento infantil e as fissuras labiopalatinas. Distúrbios da Comunicação, [S.L.], v. 33, n. I, p. 40-48, 22 fev. 2021. Pontifical Catholic University of Sao Paulo (PUC-SP). http://dx.doi.org/10.23925/21762724.2021v33irp40-48. https://revistas.pucsp.br/index.php/dic/article/view/48346. Acesso em: 12 mar. 2021. SILVEIRA, Anna Karolyne Grando et al. Estudo para detecção de fissuras labiopalatinas no pré-natal: revisão de literatura e relato de caso. Brazilian Applied Science Review, v. 4, n. $6, \quad$ p. 3959-3975, 2020. Disponível em: https://www.brazilianjournals.com/index.php/BASR/article/view/21687. Acesso em 17 mar. 2021 